\title{
25 anos de ciência para construção do SUS
}

O título deste editorial se refere ao significado mais profundo da razão de existir da Revista Ciência \& Saúde Coletiva que neste ano de 2020 faz 25 anos! Ela e a Revista Brasileira de Epidemiologia constituem os veículos com os quais a ABRASCO (que acaba de completar 40 anos) se insere na comunicação científica no Brasil e no mundo. Quem publica nos dois periódicos tem como parâmetros o mérito acadêmico, a ética em investigação, padrões, parâmetros, políticas e corpo editorial de dimensão internacional.

Ciência \& Saúde Coletiva oficialmente aderiu ao "acesso aberto" de tudo que publica, desde o seu nascimento ${ }^{1,2}$. Neste momento dá um passo a mais: pouco a pouco vai se integrando ao mundo da "ciência aberta" cujos três passos podem ser assim resumidos: aceitação de manuscritos depositados em servidores de preprints; abertura progressiva do processo de avaliação por pares; abertura e compartilhamento de dados como parte do processo de submissão de artigos. Nas edições já publicadas em 2019, incluiu-se o ORCID dos autores e iniciou-se a aceitação de artigos divulgados em preprint. Hoje os maiores e mais importantes editores de revista no mundo já aderiram ao que se convencionou chamar ciência aberta ${ }^{3,4}$.

Ao chegar aos seus 25 anos, Ciência \& Saúde Coletiva tem muito que comemorar! Hoje está em acesso aberto em 22 bases de dados nacionais e internacionais e também em sua página web (www.cienciaesaudecoletiva.com.br) e nas redes sociais: Facebook, Twitter e Instagram. Em 2019, manteve sua posição de liderança no Google Scholar como o periódico brasileiro mais citado de todas as áreas do conhecimento do país $^{1}$. Pela primeira vez, seu fator de impacto na Web of Science atingiu mais de um ponto, chegando a 1.008! Pode-se dizer que é pouco para padrões internacionais, mas é conquista para uma revista brasileira, quando se compara o cenário nacional dos periódicos. Um acontecimento marcante ocorreu em 4 de setembro de 2019: Ciência \& Saúde Coletiva recebeu um prêmio internacional, o Research Excellence Awards Brazil, concedido pelo Web of Science Group, pertencente à Editora Clarivate Analytics. A iniciativa reconheceu o bom desempenho da pesquisa brasileira, e a Revista foi contemplada na categoria "Prêmio SciELO Citation Index".

Eis alguns números do ano que acaba de terminar: em 2019 foram publicadas 12 edições com 463 artigos, sendo que 321 deles foram escritos em inglês ou traduzidos. E 21, elaborados em espanhol. No conjunto, a coleção de 2019 traz a presença de 1.666 autores brasileiros e 182 estrangeiros. Todos os resultados positivos que se apresentam e os bons augúrios para seu futuro, se devem a uma equipe coesa e comprometida que constitui o corpo editorial e o grupo executivo responsável pelo dia a dia do processo de trabalho, os revisores, os avaliadores, os autores e os leitores. É esse time unido e dedicado que faz possível a jornada que completa 25 anos.

Uma palavra muito especial para algumas instituições que sempre acreditaram na missão e na importância da Revista e que a potencializam: a Fundação Oswaldo Cruz que a cofinancia; ao SciELO que a impulsiona, ao CNPq e CAPES que mesmo em tempos de penúria endossam sua existência e à FAPERJ que em tempos melhores tem colaborado para sua implementação.

Que mais um ano seja promissor e pleno de realizações.

Maria Cecília de Souza Minayo (https://orcid.org/0000-0001-6187-9301) ${ }^{1}$

Romeu Gomes (https://orcid.org/0000-0003-3100-8091)²

Antônio Augusto Moura da Silva (https://orcid.org/0000-0003-4968-5138) ${ }^{3}$

${ }^{1}$ Escola Nacional de Saúde Pública Sérgio Arouca, Fiocruz. Rio de Janeiro RJ Brasil.

${ }^{2}$ Instituto Fernandes Figueira, Fiocruz. Rio de Janeiro RJ Brasil.

${ }^{3}$ Departamento de Saúde Pública, Universidade Federal do Maranhão. São Luís MA Brasil.

\section{Referências}

1. Minayo MCS, Gomes R, Silva AAMS. Ciência \& Saúde Coletiva entra em seu 24o ano de existência. Cien Saude Colet 2019; 24(4):1244-1244.

2. Brandão AA, Barraviera B, Correia D. SciELO: Linhas prioritárias de ação 2019-2023 [documento na internet]. SciELO 20 Anos. Disponível em: https://www.scielo20.org/redescielo/wp-content/uploads/sites/2/2018/09/Líneas-prioritarias-de-acción-2019-2023_pt.pdf

3. Packer A, Santos S. Ciência Aberta e o novo modus operandi de comunicar pesquisa. Boletim Informativo Soc Bras Cien Solo 2019; 45(1):17-24.

4. Allen C, Mehler DMA. Open science challenges, benefits and tips in early career and beyond. PLOS Biology 2019; 17(12):e3000587. 